\title{
Metoprolol and Bupropion Interaction: A Case Study
}

\section{Moody $\mathrm{DE}^{1 *}$ and Backman $\mathrm{RL}^{2}$}

${ }^{1}$ Center for Human Toxicology, Department of Pharmacology and Toxicology, University of Utah Health Science Center, Salt Lake City, UT, USA

${ }^{2}$ Division of Family Medicine, Department of Family and Preventive Medicine, University of Utah Health Science Center, Salt Lake City, UT, USA

Drug interactions can result in serious adverse responses. These are the ones we most want to avoid. Responses may also be mild and not a serious health threat. Mild responses, however, may still cause consternation to the subject. Here we present a case of a mild interaction that may have gone unexplained if the subject had not taken time to read a recent review on drug interactions [1]. While the potential for brachycardia to ensue from co-administration of bupropion and metoprolol has been previously described [2], we wish to illustrate how a low dose of bupropion and metoprolol can cause an interaction that disrupts a patient's daily activity.

\section{Case}

A 61 year-old male with an approximately 43-year history of smoking almost a pack of cigarettes per day. The subject was in fair health and had a regular exercise routine, mostly moderate, but including swimming approximately 75 minutes per week. The subject was under treatment to manage hypertension, and had been using a combination of metoprolol tartrate $(50 \mathrm{mg}, 2$ per day) and amlodipine besylate (10 $\mathrm{mg}$ one per day) for three years.

In an effort to quit smoking the subject started taking bupropion hydrochloride $(150 \mathrm{mg}$ one per day taper for 5 days and then 2 per day). Shortly after starting the medication the subject went to swim and found himself gasping for breath after only 2 laps (50 yards). After rest, he was able to swim a few more laps, but had to stop far short of his normal routine secondary to dyspnea. While this abrupt change in stamina was bewildering and confusing to the subject, he felt otherwise normal and did not seek immediate medical attention.

Fortuitously, the subject came across the review on drug interactions by Polasek et al. [1], and found bupropion listed as a strong inhibitor of cytochrome P450 (CYP) 2D6 based on the study by Kotlyar et al. showing bupropion inhibited the in vivo metabolism of dextromethorphan [3]. Metoprolol is extensively metabolized by CYP 2D6 [4-6].

The subject then discussed this case with his pharmacist. She cautioned the subject to divide his $50 \mathrm{mg}$ metoprolol tartrate tablet in half and just take one-half tablet $(25 \mathrm{mg}$ ) twice per day. The subject could still not swim his usual workout, but the length he could swim progressed and within 2-3 weeks he was back to his normal distance. Soon after this the subject had a regular appointment with his primary physician and discussed the incident with him. He concurred with the reduction in metoprolol dose. The subject subsequently had no further episodes of dyspnea with exertion, nor episodes of syncope, or cardiac symptoms.

\section{Discussion}

We have now added another example to the singular report by McCollum et al. [2] on the potential for brachycardia to arise from the interaction of bupropion and metoprolol. While such an interaction may be inferred from the metabolic route of metoprolol clearance and the effect of bupropion on CYP2D6, a clinical study demonstrating a significant effect of bupropion on the pharmacokinetics and/or pharmacodynamics of metoprolol has yet to be done. The previous case study described the incidence of severe sinus bradycardia after addition of bupropion to the medical regimen of a patient on metoprolol (75 mg twice per day). Bupropion (150 mg BID) had been administered 12 days prior to this incident [2]. In the current case, the interaction, realized in a shorter time frame, was not so severe, but illustrates how even milder drug interactions can disrupt ones daily life.

Sinus bradycardia does occur following treatment with metoprolol alone, but is not a common adverse event. In clinical trials experience with extended-release metoprolol, bradycardia was reported among the most common (greater than 2\%) adverse reactions. In the MERIT-HF study (a study in heart failure patients), bradycardia was observed in $1.5 \%$ of patients taking up to $200 \mathrm{mg}$ daily of metoprolol succinate extended-release $(n=1990)$ vs. $0.4 \%$ taking placebo $(n=2001)$ [7]. Bradycardia and shortness of breath occurred in about $3 \%$ of hypertension and angina patients receiving metoprolol tartrate immediate release. In randomized controlled studies involving patients with a history of myocardial infarction, bradycardia (heart rate less than 40 beats per minute) was seen in $15.9 \%$ of patients taking metoprolol tartrate immediate release vs. $6.7 \%$ taking placebo [8].

The probability of the interaction occurring now rests solely on clinical evidence that bupropion inhibits the in vivo metabolism of other CYP2D6 substrates including dextromethorphan, [3,9] venlafaxine [10] and imipramine [11]. In vitro studies indicate the inhibition may be due to the more potent competitive inhibition by the reductive metabolites of bupropion, erythrohydrobupropion and theohydrobupropion, rather than by the parent compound [12].

\section{Conclusion}

Bupropion is an established inhibitor of CYP2D6. We now add a second case report to illustrate the specific effect this inhibition can have on metoprolol, resulting in a mild case of bradycardia. While serious drug interactions can be life threatening, even mild interactions must be appreciated for the impact they may have on ones daily life.

\section{Financial Support}

This work was supported in part by an award from the National Institute of Justice, Office of Justice Programs, U.S. Department of Justice [Award No. 2011-DN-BX-K532]. The opinions, findings, and conclusions or recommendations expressed in this article are those of the author and do not necessarily reflect those of the Department of Justice.

\section{References}

1. Polasek TM, Lin FPY, Miners JO, Doogue MP (2011) Perpetrators of pharmacokinetic drug-drug interactions arising from altered cytochrome P450 activity: a criteria-based assessment. Br J Clin Pharmacol 71: 727-736.

*Corresponding author: Moody DE, Center for Human Toxicology, University of Utah, Salt Lake City, UT USA 84112, Tel: 801-581-5117; E-mail: david.moody@utah.edu

Received September 16, 2014; Accepted November 07, 2014; Published November 11, 2014

Citation: Moody DE, Backman RL (2014) Metoprolol and Bupropion Interaction: A Case Study. Clin Exp Pharmacol 4: 165. doi:10.4172/2161-1459.1000165

Copyright: $\odot 2014$ Moody DE, et al. This is an open-access article distributed under the terms of the Creative Commons Attribution License, which permits unrestricted use, distribution, and reproduction in any medium, provided the original author and source are credited. 
Citation: Moody DE, Backman RL (2014) Metoprolol and Bupropion Interaction: A Case Study. Clin Exp Pharmacol 4: 165. doi:10.4172/21611459.1000165

2. McCollum DL, Greene JL, McGuire DK (2004) Severe sinus bradycardia after initiation of bupropion therapy: a probable drug-drug interaction with metoprolol. Cardiovasc Drugs Ther 18: 329-330.

3. Kotlyar M, Brauer LH, Tracy TS, Hatsukami DK, Harris J, et al. (2005) Inhibition of CYP2D6 activity by bupropion. J Clin Psychopharmacol 25: 226-229.

4. Lennard MS, Silas JH, Freestone S, Ramsay LE, Tucker GT, et al. (1982) Oxidation phenotype-a major determinant of metoprolol metabolism and response. New Engl J Med 307: 1558-1560.

5. Otton SV, Crewe HK, Lennard MS, Tucker GT, Woods HF (1988) Use of quinidine inhibition to define the role of the sparteine/debrisoquine cytochrome P450 in metoprolol oxidation by human liver microsomes. J Pharmacol Exp Ther 247: 242-247.

6. Mautz DS, Nelson WL, Shen DD (1995) Regioselective and stereoselective oxidation of metoprolol and bufuralol catalyzed by microsomes containing cDNA-expressed human P4502D6. Drug Metab Dispos 23: 513-517.
7. Astra Zeneca L (2010) Product Information: TOPROL-XL(R) oral extended release tablet, metoprolol succinate oral extended release tablet.

8. Corporation NP (2009) Product Information: Lopressor(R) oral tablets, IV injection, metoprolol tartrate oral tablets, IV injection.

9. Guzey C, Norstrom A, Spigset O (2002) Change from the CYP2D6 extensive metabolizer to the poor metabolizer phenotype during treatment with bupropion. Ther Drug Monit 24: 436-437.

10. Kennedy SH, McCann SM, Masellis M, Mclntyre RS, Raskin J, et al. (2002) Combining bupropion SR with venlafaxine, paroxetine, or fluoxetine: a preliminary report on pharmacokinetic, therapeutic, and sexual dysfunction effects. J Clin Psychiatry 63: 181-186.

11. Shad MU, Preskorn SH. (1997) A possible bupropion and imipramine interaction. J Clin Psychopharmacol 17: 118-119.

12. Reese MJ, Wurm RM, Muir KT, Generaux GT, St John-Williams L, et al. (2008) An in vitro mechanistic study to elucidate the desipramine/bupropion clinical drug-drug interaction. Drug Metab Dispos 36: 1198-1201. 